\title{
Synthesis of Carbon Nanomaterials Using High-Voltage Electric Discharge Techniques
}

\author{
A. D. Rud, N. I. Kuskova, L. I. Ivaschuk, \\ L. Z. Boguslavskii and A. E. Perekos \\ G. V. Kurdyumov Institute for Metal Physics of NASU, \\ Institute of Pulse Research and Engineering of NASU, \\ Ukraine
}

\section{Introduction}

New spatial forms of carbon - fullerenes, nanotubes, graphene, etc., attract significant interest since the time of their discovery due to their unique physicochemical and mechanical properties (Afanas'ev et al., 2001; Gogotsi, 2006; Guozhong Cao, 2004; Eletskii \& Smirnov, 1995; Shenderova et al., 2002). A lot of investigations have been carried out in this field for the recent years. Hence, the problems of the development of effective synthesis, separation and purification methods for carbon nanomaterials (CNM) remain importance. Therefore, it is of special interest to clarify the possibility of application of electric discharge techniques, such as the electric wires explosion (EWE) (Kuskova, 2005; Kuskova et al., 2010; Rud et al., 2007, 2011), the spark erosion of materials (Bulgakov et al., 2009; Rud et al., 2007), developed for manufacturing metallic nanopowders, and the electric breakdown of dielectric liquids (EBOL) (Rud et al., 2011) for synthesis of CNM and investigation of structural and physical properties of synthesized materials.

The physical basis of electric discharge technology of synthesis of different forms of CNM consists in the injection into working medium- a source of carbon, energy need for its heating, evaporation and destruction through a passage of powerful (up to $1 \mathrm{MA}$ ) current pulses with frequencies of $0.1-10 \mathrm{~Hz}$. As a result, structural and phase transformations of carbon or destruction of molecules of organic liquids on individual fragments take place with their subsequent ultrafast cooling and synthesis of different types of CNM. Thus, it is possible to control effectively the structural and phase state of the synthesized CNM by the followings:

- variation of the injected into working medium energy by changing the energy deposited in the capacitor bank and the number of current pulses;

- selection of the working medium - a source of carbon ( using graphite conductors of different geometry or hydrocarbons with different chemical nature).

Electric explosions of graphite conductors were performed in different cooling media (ethanol, toluene, hexane) in the interval of deposited energies of capacitor bank $W_{0}$ from 0.1 to $45 \mathrm{~kJ}$ and the inductance of the discharge circuit $L$ from 1 to $50 \mu \mathrm{H}$. Charging voltage $U_{0}$ and capacitance $C$ of the capacitor bank was varied from 10 to $50 \mathrm{kV}$ and from 1 to $36 \mu \mathrm{F}$, respectively. The electrical circuit of the experimental setup is shown in Fig. 1. The use of 
graphite conductors with different diameters and lengths enables to vary the value of injected specific energy into the substance (per unit mass of graphite) from 1 to $300 \mathrm{~kJ} / \mathrm{g}$. There are two kinds of electric explosion (EE) modes which depend on the value of the specific energy $w$ injected into the conductor: low-energy if $\mathrm{w}<\mathrm{w}_{\mathrm{s}}$, and high-energy if $\mathrm{w}>\mathrm{w}_{\mathrm{s}}$, where $w_{s}$ is graphite sublimation specific energy $(62 \mathrm{~kJ} / \mathrm{g})$.

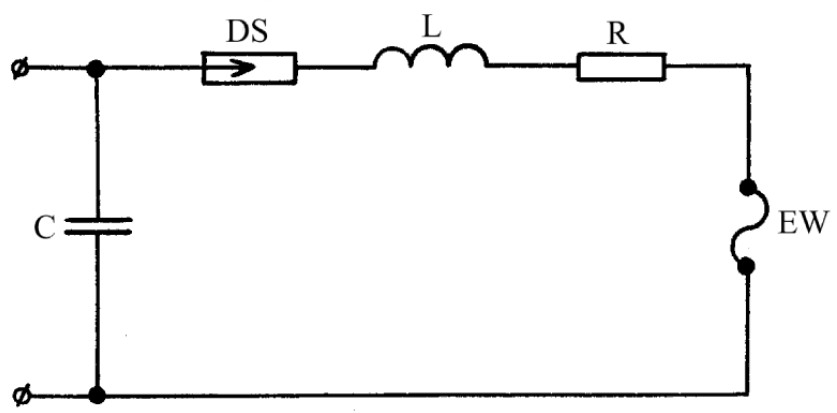

Fig. 1. RLC- electrical circuit with an exploding conductor:

C - capacitor bank,

DS - discharge switch,

$\mathrm{L}$ - inductance,

$\mathrm{R}$ - resistance,

EW - exploding wire (conductor).

The method of electrical breakdown of organic liquids has been implemented on the electrical equipment (Fig. 2). The electric-discharge reactor is filled out with liquids, differ by degree of hybridization of carbon atoms in the molecule, but with the same number of carbon atoms contained in the ring:

- benzene $\mathrm{C}_{6} \mathrm{H}_{6}$ - belongs to arenes with $s p^{2}$-hybridisation of carbon atoms in planar ring molecule;

- cyclohexane $\mathrm{C}_{6} \mathrm{H}_{12}$ - belongs to alkanes with $s p^{3}$-hybridisation of carbon atoms in nonplanar ring molecule.

The indicated organic liquids are non-polar dielectrics with a zero dipole moment (Speight, 2004).

The working liquid with colloidal solution of carbon nanoparticles is decanted from the reactor and centrifugated during 0.3-2 hours after series of breakdowns (up to 50,000 pulses). The produced material is exsiccated at the sparing temperatures (up to $500 \mathrm{~K}$ ) with a purpose to form dry powder.

X-Ray data were collected using diffractometer HZG-4 with filtered $\mathrm{Cu} \mathrm{Ka}$ or $\mathrm{Co} \mathrm{Ka}$ radiations and standard powder diffractometer with monochromatic Mo Ka radiation (primer pirographite monochromator). Electron microscopy investigations were performed on the high resolution microscopes JEOL JEM-2100F and LEO SUPRA 50VP. Raman spectroscopy analysis was conducted at room temperature on Horiba Jobin-Yvon T64000 spectrometer $(\lambda=514 \mathrm{~nm})$, mass spectra - on the high resolution mass spectrometer MX-1320 with field ion source. The magnetic properties were measured by means of the ballistic method in the magnetic field ranged from 0 to $800 \mathrm{kA} / \mathrm{m}$ at temperature interval of 77 to $673 \mathrm{~K}$. 


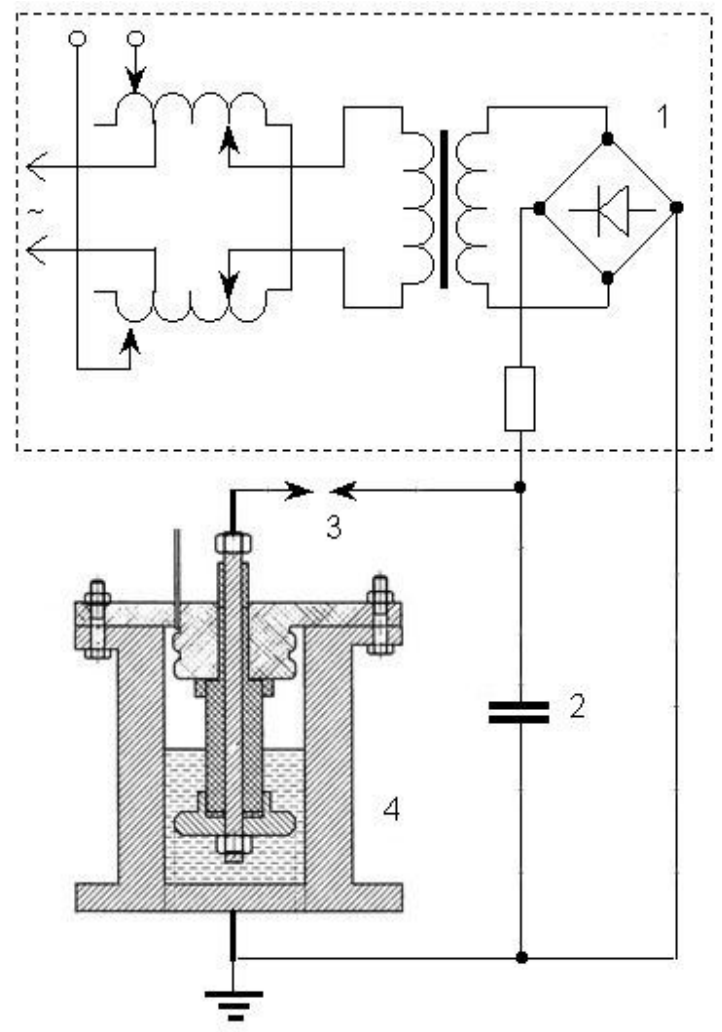

Fig. 2. Block-scheme of the high-voltage electric-discharge facility and reactor:

1 - charging unit,

2 - pulse energy storage system (capacitor bank),

3 - discharge switch,

4 - discharge reactor with organic liquid.

\section{Phase composition of carbon nanomaterials produced by the method of electrical explosion of graphite conductors}

\subsection{Physical aspects of synthesis of new carbon allotropes by an electric explosion technique}

The electrical wires explosion is one of the most powerful techniques for pulse action on a substance that results of rapid transformation of the electric field energy into internal energy of conductor matter. It is a wide used technology for production of metallic nanopowders. Exploding material is subjected to the combined impact of high temperature and pressure $\left(\sim 10^{5} \mathrm{~K}\right.$ and $\sim 5 \cdot 10^{2} \mathrm{MPa}$, respectively), electrical and magnetic fields. It was proposed (Kuskova, 2005; Kuskova et al., 2010; Rud et al., 2007, 2011) to utilize EWE technique for synthesis of carbon nanomaterials in consequence of structural transformations graphite $\rightarrow$ diamond, graphite $\rightarrow$ nanotubes or graphite $\rightarrow$ fullerenes due to heating of graphite rods by powerful current pulse. 
The analytical time profiles $\mathrm{T}(\mathrm{t})$ and $\mathrm{P}(\mathrm{t})$ and phase trajectories at carbon phase diagram should be calculated for different electroexplosion modes of graphite rods to predict the phase compositions of the obtained products. Let us consider the behavior of conductor (graphite rod) at the EE process. It starts from homogeneous heating of solid conductor to melt point. A specific electric conductivity of material changes during melting process and results the change of current flowing through the conductor. Liquid conductor continues to heat holding its shape because the time of the progress of hydrodynamic instabilities exceeds a task time scale $\left(\mathrm{t}>10^{-8} \mathrm{c}\right)$. A pressure inside of conductor has magnetic and gaskinetic components.

The system of equations, that simulates the process of heating of a solid cylindrical conductor that expands or liquid conductor which does not undergo phase transformations in an electric circuit with capacity $\mathrm{C}$ and inductance L, has the following form (Kuskova, 1997):

$$
\begin{aligned}
& \frac{\partial \rho}{\partial t}+\frac{1}{r} \frac{\partial(\rho r v)}{\partial r}=0 \\
& \rho\left(\frac{\partial \mathrm{v}}{\partial \mathrm{t}}+\mathrm{v} \frac{\partial \mathrm{v}}{\partial \mathrm{r}}\right)=-\frac{\partial \mathrm{P}}{\partial \mathrm{r}}-\frac{1}{2 \mu \mathrm{r}^{2}} \frac{\partial\left(\mathrm{r}^{2} \mathrm{~B}_{\varphi}^{2}\right)}{\partial \mathrm{r}} \\
& \rho\left(\frac{\partial \varepsilon}{\partial \mathrm{t}}+\mathrm{v} \frac{\partial \varepsilon}{\partial \mathrm{r}}\right)=-\mathrm{P} \frac{1}{\mathrm{r}} \frac{\partial(\mathrm{rv})}{\partial \mathrm{r}}+\frac{\mathrm{j}^{2}}{\sigma} \\
& \frac{\partial \mathrm{B}_{\varphi}}{\partial \mathrm{t}}+\frac{\partial\left(\mathrm{vB}_{\varphi}\right)}{\partial \mathrm{r}}=\frac{1}{\mu \sigma} \frac{\partial}{\partial \mathrm{r}}\left(\frac{1}{\mathrm{r}} \frac{\partial\left(\mathrm{rB}_{\varphi}\right)}{\partial \mathrm{r}}\right) \\
& \frac{\mathrm{d}^{2}(\mathrm{LI})}{\mathrm{dt}^{2}}+\frac{\mathrm{d}(\mathrm{RI})}{\mathrm{dt}}+\frac{\mathrm{I}}{\mathrm{C}}=0 \\
& \rho=\rho_{0}\left[1-\alpha\left(T-T_{0}\right)\right] \\
& \sigma=\frac{\sigma_{0}}{1+\beta\left(T-T_{0}\right)}\left(\frac{\rho}{\rho_{0}}\right)^{\gamma}
\end{aligned}
$$

where $\rho$ - density, $\mathrm{P}$ - pressure, $\varepsilon$ - specific internal energy, $\mathrm{T}$ - temperature, $\alpha$ - thermal expansion coefficient, $\rho_{0}$ - density of conductor's matter at the initial temperature $T_{0}, \sigma_{0}-$ specific electroconductivity of conductor's matter at the temperature $T_{0}, \beta$ - temperature coefficient of electroconductivity, $\gamma$ - coefficient, $\mu$ - magnetic permeability, $B_{\varphi}$ - magnetic induction component.

The obtained solutions for the system of equations (1) - (7) of solid and liquid phases allow (after exclusion of the time from dependences $P(t)$ and $T(t)$ ) to find the phase trajectory of matter in the process of homogenous heating of conductor by powerful current pulse $(\mathrm{P}, \mathrm{T}-$ terms): 


$$
\begin{gathered}
\mathrm{P}(\mathrm{T}) \approx \frac{\mu}{4 \pi^{2} \mathrm{a}_{0}^{2}}\left(\frac{\mathrm{mc}_{0} \mathrm{U}_{0}\left(\mathrm{~T}-\mathrm{T}_{0}\right)}{\mathrm{R}_{0} \mathrm{~L}}\right)^{2 / 3}\left(1-\frac{\mathrm{r}^{2}}{\mathrm{a}_{0}{ }^{2}}\right) \text { for } T<T_{m} \\
\mathrm{P}^{0} \approx \frac{\mathrm{k}_{\mathrm{m}}^{2} \mu}{4 \pi^{2} \mathrm{a}_{0}^{2}}\left(\frac{\mathrm{mc}_{0} \mathrm{U}_{0}\left(\mathrm{~T}_{\mathrm{m}}-\mathrm{T}_{0}\right)}{\mathrm{R}_{0} \mathrm{~L}}\right)^{2 / 3}\left(1-\frac{\mathrm{r}^{2}}{\mathrm{a}_{0}{ }^{2}}\right) \text { for } T=T_{m} \\
\mathrm{P}(\mathrm{T}) \approx \mathrm{P}^{0} \approx \text { const for } T_{m}<T<T_{b},
\end{gathered}
$$

where $\mathrm{k}_{\mathrm{m}}$ - coefficient, $1<\mathrm{k}_{\mathrm{m}}<3$; $\mathrm{a}_{0}$ - initial radius of conductor; $\mathrm{m}$-mass of conductor; $c_{0}$ - specific heat capacity at the initial temperature $T_{0} ; R_{0}$ - resistance at the $T_{0} ; T_{m}$ - melting temperature; $\mathrm{T}_{\mathrm{b}}$ - boiling temperature; $\mathrm{P}^{0}$ - maximum pressure.

Transition to specific characteristics of the matter enables to obtain the following expression of the maximum magnetic pressure:

$$
\mathrm{P}^{0}=\frac{\mathrm{k}_{\mathrm{m}}^{2} \mu}{4}\left(\frac{\sigma_{0} \rho_{0} \mathrm{c}_{0} \mathrm{U}_{0}\left(\mathrm{~T}_{\mathrm{m}}-\mathrm{T}_{0}\right) \mathrm{a}_{0}}{\pi \mathrm{L}}\right)^{2 / 3}\left(1-\frac{\mathrm{r}^{2}}{\mathrm{a}_{0}{ }^{2}}\right) \text { for } T_{m}<T<T_{b}
$$

Further heating of liquid conductor by current pulse leads to its evaporation in the form of explosion. A secondary discharge initiation in the electroexplosion products results the formation of the plasma channel and shock waves generation. Fast expansion of gas-vapor cavity, condensation of electroexplosion products and synthesis of nanosized particles of initial material or new materials takes place after current termination depending on physicochemical properties of the medium and time-energy parameters of electroexplosion. Therefore, the electrical parameters of the experimental apparatus (Fig.1) and explosion conductor required to achieve $\mathrm{P}, \mathrm{T}$-conditions of phase transformation can be calculated using the expressions (8)-(11). It is possible to control an explosion process through these parameters and properties of environment media in reactor to produce nanosized particles in different structural state.

\subsection{Phase trajectories of carbon in process of electroexplosion}

At the initial stage of the fast ( 1-5 $\mu$ s endurance) elecroexplosion, magnetic pressure in a conductor exceed gas-kinetic one considerably and rise their top values. For so called lowenergy modes of EE (injected into explosion material energy is less than sublimation energy), the value of the maximum pressure in centre of graphite conductor, calculated by expressions (8)-(11) or experimentally measured, does not exceed $20 \mathrm{MPa}$. According to the phase diagram of graphite, liquid phase does not appear at these $\mathrm{P}, \mathrm{T}$ conditions but only the partial sublimation of graphite in the form of carbon clusters or graphene sheets occurs. Hence, a lowenergy mode of EE with a current break because of the formation of the nonconductive gasvapor carbon cave should be realized for synthesis fullerenes or carbon nanotubes. The mentioned synthesis occurs after breakdown of hot ionized gas of carbon clusters.

For high-energy modes of EE (injected into explosion material energy essentially exceed sublimation energy), the value of the maximum pressure in the centre of the conductor is about $10 \mathrm{GPa}$ that is possible to expense gas-kinetic or reactive pressure. The reactive pressure comes from the evaporation of the wave spreading from the surface into the conductor body and shock waves spreading from the discharge channel at the secondary 
breakdown in an electroexplosion process. Condensation of liquid carbon at these $\mathrm{P}, \mathrm{T}$ conditions can result in diamond synthesis.

The phase trajectories of carbon at phase diagrams for different kinds of graphite conductor electroexplosion (low- and high-energy) can be calculated using expressions (8)-(11) and estimating thermodynamic conditions in gas-vapor cave (Fig.3). The phase trajectories for central layers of the graphite rod of the high-energy electroexplosion experiments correspond to phase transition graphite $\rightarrow$ diamond and they are plotted in the Fig. 3 (curves 1,2). The trajectory 1 matches to immediate phase transition graphite $\rightarrow$ diamond, what is impossible at conditions this work owing to deficit of capacitor deposited energy injected into graphite rod. The curve 2 corresponds to conditions of the high-energy mode of these experiments when phase trajectory of carbon can be described as sequence of graphite $\rightarrow$ liquid carbon $\rightarrow$ diamond transitions. For comparison, the phase trajectory of carbon for the low-energy mode, when electric breakdown of carbon gas realizes in EE process without melting of graphite conductor, is plotted in the Fig. 3 (curve 3).

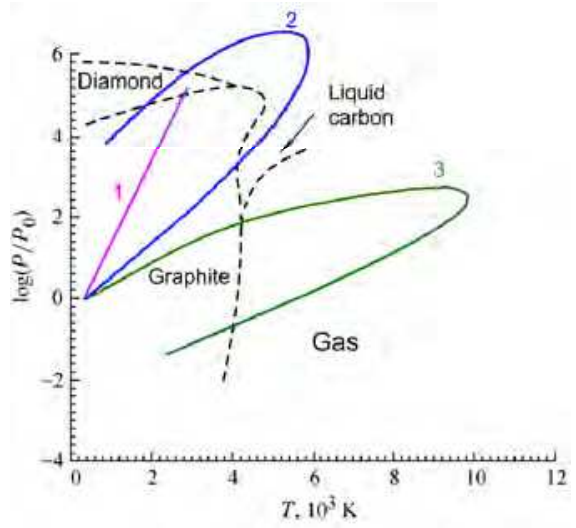

Fig. 3. Carbon phase diagram (dashes - lines of phase equilibrium) and phase trajectories of carbon at graphite electroexplosion (1,2 - transition graphite $\rightarrow$ diamond, 3 - graphite $\rightarrow$ fullerenes).

It can be seen from Fig. 3 that extreme conditions occuring in a process of low- or highenergy modes of graphite electroexplosion match to diapason of thermodynamic parameters required for high-probability spontaneous formation of new phases of carbon. The synthesized phases at these conditions can possess amorphous, nano- or microcrystalline structure. A size of individual particles strongly depends on parameters of EE process. The produced nanostructures are susceptible to the relaxation in the case of quenching conditions of nonobservance.

\subsection{Technological conditions of nanocarbon allotropes synthesis during graphite electroexplosion}

It makes possible to find a correlation between electrical parameters of experimental apparatus, size and properties of an exploded graphite rod and required thermodynamic 
parameters for synthesis of new allotropes of carbon. The mechanism for synthesis of diamond and fullerenes is considered below in order to clarify the conditions of their manufacture by EWE technique.

The first stage of the synthesis of fullerenes and nanotubes in EE process is a destruction of graphite layered structure on separated graphene sheets containing various defects including broken covalent bonds between carbon atoms which results from fast Joule heating. It leads to the formation of pentagonal cycles in the structure of the graphene sheet required for its folding in fullerene-like cage. Therefore, the injected into graphite conductor specific energy w should be several times lower than sublimation energy of graphite $\mathrm{w}_{\mathrm{s}}$. The conditions of partial sublimation of graphite to the graphene sheets and clusters from thermodynamic point of view $\left(\mathrm{P}<10^{7} \mathrm{~Pa}, \mathrm{~T}<5 \cdot 10^{3} \mathrm{~K},(\mathrm{dP} / \mathrm{dT})_{1}<2 \cdot 10^{3} \mathrm{~Pa} / \mathrm{K}\right)$ can be realized at a low-energy mode of $\mathrm{EE}$. At the second stage of $\mathrm{EE}$, at the conditions of $\mathrm{P} \approx 10^{3} \mathrm{~Pa}$ and $\mathrm{T} \approx 2 \cdot 10^{3} \mathrm{~K}$ in the fast expanded gas-vapor cave, an assemblage of various clusters into fullerene molecule or graphite sheet folding into nanotube occurs.

The synthesis of diamond proceeds in conditions of a high-energy mode of EE and it associates with two stages. The first stage is fast compression of graphite due to pinch-effect (the compression of a plasma filament by the magnetic forces), melting the central part of the conductor and the formation of liquid carbon $\left(\mathrm{P}>10^{10} \mathrm{~Pa}, \mathrm{~T}>5 \cdot 10^{3} \mathrm{~K},(\mathrm{dP} / \mathrm{dT})_{2}>\right.$ $\left.2 \cdot 10^{6} \mathrm{~Pa} / \mathrm{K}\right)$. Injected energy $\mathrm{W}$ into a graphite rod should be greater than total sublimation energy of the whole sample $W_{\mathrm{s}}$. At the second stage, a fast cooling results in crystallization of liquid carbon in diamond.

Given limitations (from above and from below) for the rate of the change of the pressure $\mathrm{dP} / \mathrm{dT}$ in the central part of the conductor during EE process allow to find a correlation between the phase composition of the CNM synthesized, velocity of the current increase and current density in the conductor. A range at the phase diagram where the exploding substance falls is characterized by both the temperature increased owing to Joule heating and magnetic pressure. It can be estimated for the low-expanding cylinder conductor from the equation (Kuskova, 2005):

$$
\frac{\partial \mathrm{P}}{\partial \mathrm{r}}=-\frac{1}{2 \mu \mathrm{r}^{2}} \frac{\partial}{\partial \mathrm{r}}\left(\mathrm{r}^{2} \mathrm{~B}_{\varphi}^{2}\right)
$$

For homogeneous heating of a conductor the magnetic induction $\mathrm{B} \varphi$ is:

$$
\mathrm{B}_{\varphi}=\frac{\mu \mathrm{I}}{2 \pi \mathrm{a}^{2}} \mathrm{r}=\frac{\mu \mathrm{jr}}{2}
$$

where I - current, a - conductor radius, $\mathrm{j}$ - current density, $\mu$ - magnetic permeability.

The solution of equation (12) is of the form:

$$
\mathrm{P}(\mathrm{r})=\mathrm{P}(\mathrm{a})+\frac{1}{4} \mu \mathrm{j}^{2}\left(\mathrm{a}^{2}-\mathrm{r}^{2}\right)
$$

where $\mathrm{P}(\mathrm{a})$ - pressure at the conductor surface.

The rates of change of top pressure (in the centre of conductor at $r=a$ ) and temperature in a solid cylinder conductor can be evaluated from the expressions:

$$
\frac{\partial \mathrm{P}}{\partial \mathrm{t}} \approx \frac{1}{2} \mathrm{a}^{2} \mu \mathrm{j} \frac{\partial \mathrm{j}}{\partial \mathrm{t}} \approx \mathrm{a}^{2} \mu \frac{\mathrm{j}^{2}}{2 \tau}
$$




$$
\frac{\partial T}{\partial \mathrm{t}} \approx \frac{j^{2}}{\sigma \rho c}
$$

where $\tau$ - current rise time to the top magnitude, $\sigma$ - specific conductivity, $c-$ specific heat capacity, $\rho$ - density.

From expressions (15) and (16) we get

$$
\frac{\partial \mathrm{P}}{\partial \mathrm{T}}=\frac{\mu \sigma \rho \mathrm{c}}{2 \pi \mathrm{j}} \frac{\mathrm{d}}{\mathrm{dt}}
$$

Based on the pointed out limitations for $(\mathrm{dP} / \mathrm{dT})_{1,2}$ and the expression (17), the relations between current density and its rate of the rise need to synthesis of diamond (18) and fullerenes (19) can be written as:

$$
\begin{aligned}
& \mathrm{j}<\mathrm{k}_{1} \sigma \rho c \mu(\mathrm{dI} / \mathrm{dt}) \\
& \mathrm{j}>\mathrm{k}_{2} \sigma \rho c \mu(\mathrm{dI} / \mathrm{dt})
\end{aligned}
$$

where $\mathrm{k}_{1,2}=\left[2 \pi(\mathrm{dP} / \mathrm{dT})_{1,2}\right]^{-1}$.

As the synthesis of diamond from graphite phase is stipulated by high pressure, the rate of the current rise in the conductor is a crucial controlling factor as it is evident from (18). When the current density increases (in a thin conductor), the intensity of heating of the conductor rises as well that results in the sublimation of graphite at a low pressure. Substituting the graphite characteristic values into (18) and (19), the following conditions are obtained for synthesis of:

$$
\begin{aligned}
& \text { diamond }-\mathrm{j}<\mathrm{k}_{3}(\mathrm{dI} / \mathrm{dt}) \text {, where } \mathrm{k}_{3}=10^{-1} \mathrm{~s} / \mathrm{m}^{2} \\
& \text { fullerenes }-\mathrm{j}>\mathrm{k}_{4}(\mathrm{dI} / \mathrm{dt}) \text {, where } \mathrm{k}_{4}=10^{2} \mathrm{~s} / \mathrm{m}^{2}
\end{aligned}
$$

From expressions (18) and (19) approximate relations between the conductor radius a and the capacity of capacitor batteries $C$ can be obtained. Using the sinusoidal dependence of current, which is valid for beginning of phase transformation, allows to find $\mathrm{j}, \mathrm{dI} / \mathrm{dt}$ and their ratio:

$$
\frac{\mathrm{j}}{\mathrm{dI} / \mathrm{dt}}=\frac{\sqrt{\mathrm{LC}}}{\pi \mathrm{a}^{2}} \operatorname{tg} \frac{\mathrm{t}}{\sqrt{\mathrm{LC}}}
$$

Then the synthesis conditions of new carbon phases which are similar to (20) and (21) can be given as:

$$
\begin{aligned}
& \text { for diamond }-\sqrt{\mathrm{LC}}<\mathrm{k}_{3} \pi \mathrm{a}^{2} \operatorname{ctg}(\mathrm{t} / \sqrt{\mathrm{LC}}) \\
& \text { for fullerenes - } \sqrt{\mathrm{LC}}>\mathrm{k}_{4} \pi \mathrm{a}^{2} \operatorname{ctg}(\mathrm{t} / \sqrt{\mathrm{LC}})
\end{aligned}
$$

As modes of energy injection are usually chosen such that the phase transformations (melting or sublimation) occur in the interval of $\pi / 4<\mathrm{t} / \sqrt{\mathrm{LC}}<\pi / 3$, then 
$\operatorname{ctg}(t / \sqrt{L C}) \approx 1$. Taking into account a ratio of injected energy $w$ into the graphite conductor and its sublimation one $\mathrm{w}_{\mathrm{s}}$, the synthesis conditions can be received:

$$
\begin{aligned}
& \text { for diamond }-\sqrt{\mathrm{LC}}<\mathrm{k}_{3} \pi \mathrm{a}^{2}, \mathrm{w}>\mathrm{w}_{\mathrm{s}} \\
& \text { for fullerenes }-\sqrt{\mathrm{LC}}<\mathrm{k}_{4} \pi \mathrm{a}^{2}, \mathrm{w}<\mathrm{w}_{\mathrm{s}}
\end{aligned}
$$

Using expressions (25) and (26) enables to forecast the phase composition of synthesized carbon nanomaterials without oscillographic testing of electroexplosion process.

\subsection{Structure state and magnetic properties of carbon nanomaterials produced by the method of electrical explosion of graphite conductors}

It was theoretically shown in 2.1-2.3 that extreme conditions arising at the electroexplosion of the graphite conductor conform to the thermodynamic parameters of the new carbon allotropes formation. The interaction of powerful current pulses with solid matter occurs at two stages. The first stage is heating, melting and evaporation of the matter in the equilibrium state. The second stage is nonequilibrium processes of ionization and condensation of EE products. Synthesis of new carbon forms can happen at the both stages. To verify the expressions (25) and (26) obtained in the part 2.3, the EE experiments of highenergy and low-energy modes were performed at the experimental setup (Fig. 1) with the oscillographic records of current I and voltage U pulses (Fig. 4).

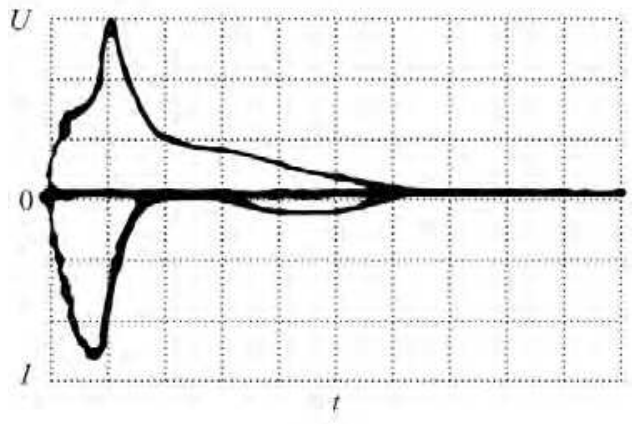

(a)

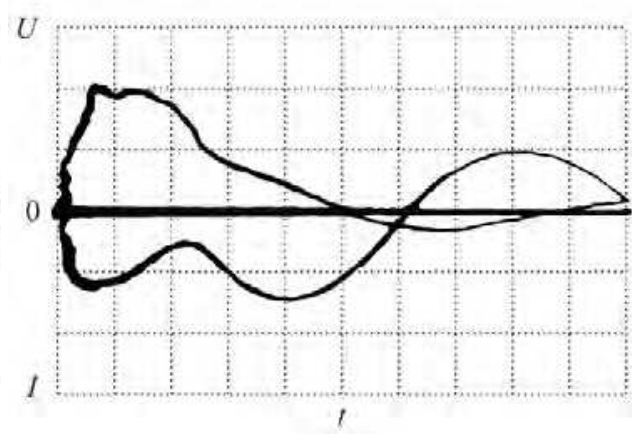

(b)

Fig. 4. Typical oscillograms of voltage (top) and current (down) for different modes of electrical explosion of graphite conductors:

a) $\mathrm{U}_{0}=30.5 \mathrm{kV}, a=0.15 \mathrm{~mm} ; \mathrm{m}_{\mathrm{t}}=2 \mu \mathrm{s} /$ cell, $\mathrm{m}_{\mathrm{u}}=10 \mathrm{kV} /$ cell, $\mathrm{m}_{\mathrm{i}}=2.2 \mathrm{kA} /$ cell,

b) $\mathrm{U}_{0}=25 \mathrm{kV}, a=1 \mathrm{~mm} ; \mathrm{m}_{\mathrm{t}}=2 \mu \mathrm{s} /$ cell, $\mathrm{m}_{\mathrm{u}}=10 \mathrm{kV} /$ cell, $\mathrm{m}_{\mathrm{i}}=8.7 \mathrm{kA} /$ cell.

The typical oscillogram for a low-energy mode of graphite electroexplosion with the secondary breakdown of evaporated carbon gas after current pause is shown in Fig. 4a. The high-energy EE mode with melting of the central part of the graphite rod and subsequent electrical breakdown of the evaporated surface layers is given at Fig. $4 \mathrm{~b}$. The values of $\mathrm{dI} / \mathrm{dt}$ and $\mathrm{j}$ are estimated at the point of the phase transitions when current has a maximum value. 
The experimental results of the synthesis products of graphite electroexplosion are presented in Fig. 5-8. The synthesis of a diamond-like phase occurs during electrical explosion of graphite at a high-energy mode realized in hexane with the following parameters found from the oscillogram (Fig. $4 \mathrm{~b}$ ): the injected specific energy $\mathrm{w}$ into the conductor $>100 \mathrm{~kJ} / \mathrm{g}$; the current density $\mathrm{j}$ is about $10^{9} \mathrm{~A} / \mathrm{m}^{2}$ and the rate of the current rise $\mathrm{dI} / \mathrm{dt}$ is about $10^{10} \mathrm{~A} / \mathrm{s}$, and it satisfies to (20). The typical XRD pattern is shown in Fig. 5. It is clearly seen, that the phase composition of the produced CNM consists of the ordinary graphite and the cubic diamond (space group $\mathrm{Fd} 3 \mathrm{~m}$ ). Further decreasing injected energy to $\mathrm{w} \approx 62 \mathrm{~kJ} / \mathrm{g}$ leads to synthesis of a mixture of ordinary graphite and lonsdalite (hexagonal modification of diamond with space group $\mathrm{P} 63 / \mathrm{mmc}$ ).

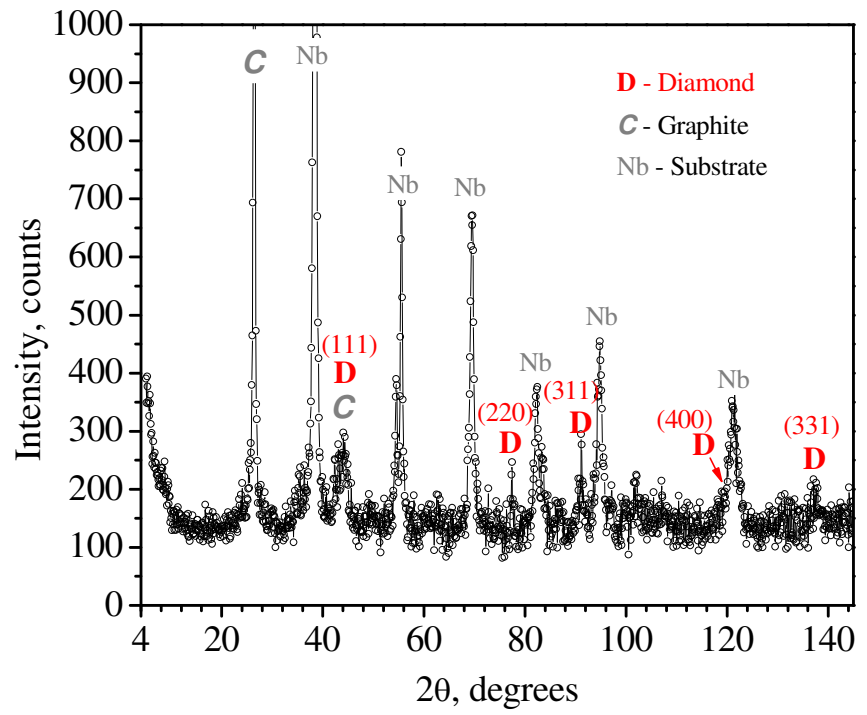

Fig. 5. X-Ray diagram of product of electrical explosion of graphite rod at $w \approx 100 \mathrm{~kJ} / \mathrm{g}$ in hexane ( $\mathrm{Cu} \mathrm{K} \alpha$ radiation).

According to the condition (26), the further decrease of specific energy injected into the graphite conductor (realization of the low-energy mode, Fig. 4a) enables to reach the thermodynamic parameters which are necessary for the synthesis of fullerenes and carbon nanotubes during EE process ( $\mathrm{P} \sim 10^{3} \mathrm{~Pa}, \mathrm{~T} \sim 2 \cdot 10^{3} \mathrm{~K}$ ). The building of fullerene molecules from carbon cluster or folding of graphene sheets in the nanotubes occurs in the second phase of the electrical explosion in a fast expanding carbon evaporated cave and it depends on the size of the cluster (a higher $\mathrm{w}$ reflects to a smaller cluster size).

An electron microscopy investigation of CNM produced at low-energy parameters $(8 \mathrm{~kJ} / \mathrm{g}<\mathrm{w}<10 \mathrm{~kJ} / \mathrm{g})$ shows the presence of nanographite and carbon nanotubes (Fig. 6). Carbon nanotubes are aggregated at bunches with the diameters up to $20 \mathrm{~nm}$ and the length up to $5 \mu \mathrm{m}$. It is important to note that the separate nanotubes have composite structure and hierarchical organization. In the products of electric explosion of graphite in the hexane, fragments of graphene sheets are present (Fig. 6b). 

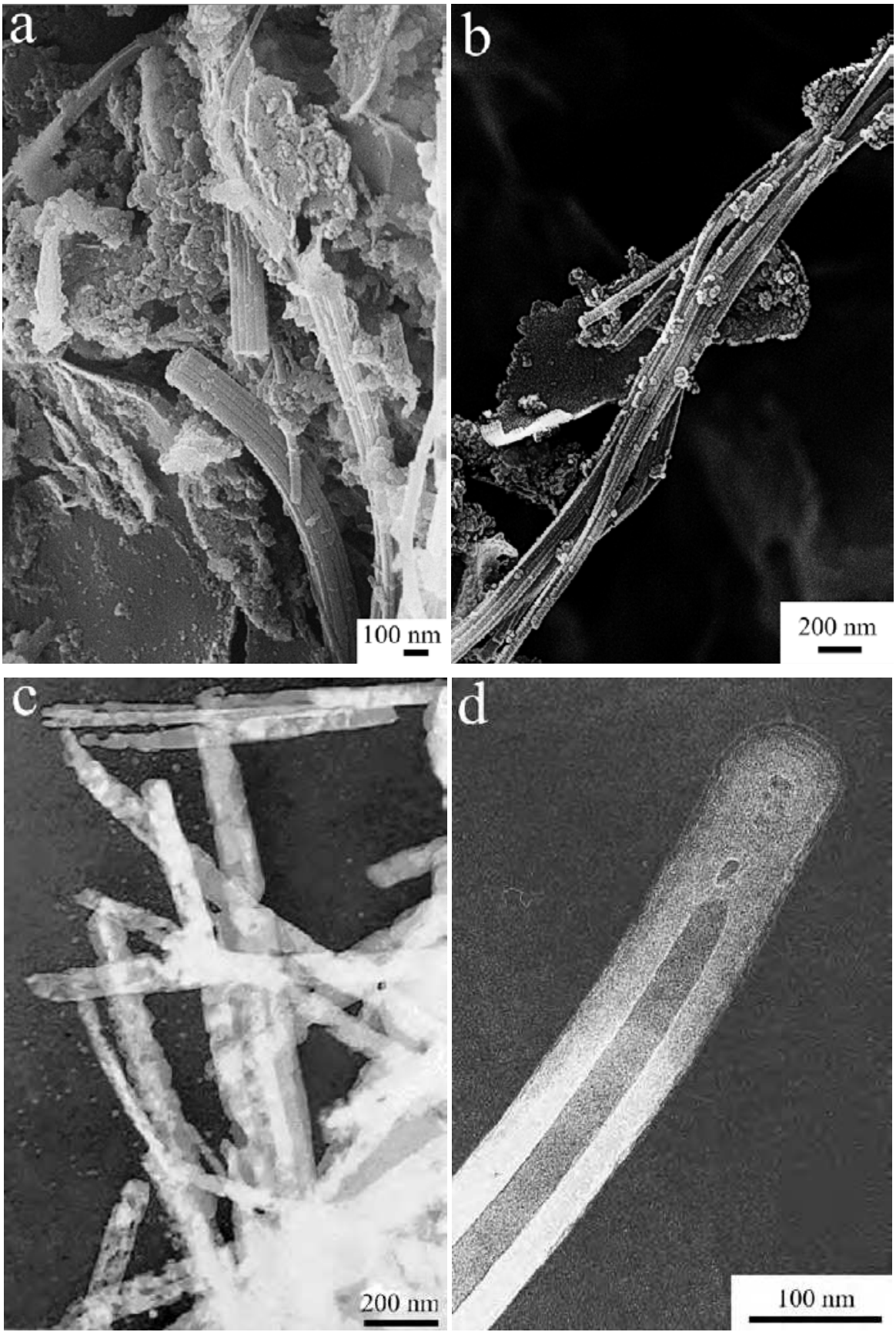

Fig. 6. Electron microscope images of the products of electrical explosion of graphite in hexane $(\mathrm{a}, \mathrm{b})$ and toluene $(\mathrm{b}, \mathrm{c})$ with injected energy $8 \mathrm{~kJ} / \mathrm{g}<\mathrm{w}<10 \mathrm{~kJ} / \mathrm{g}$. 

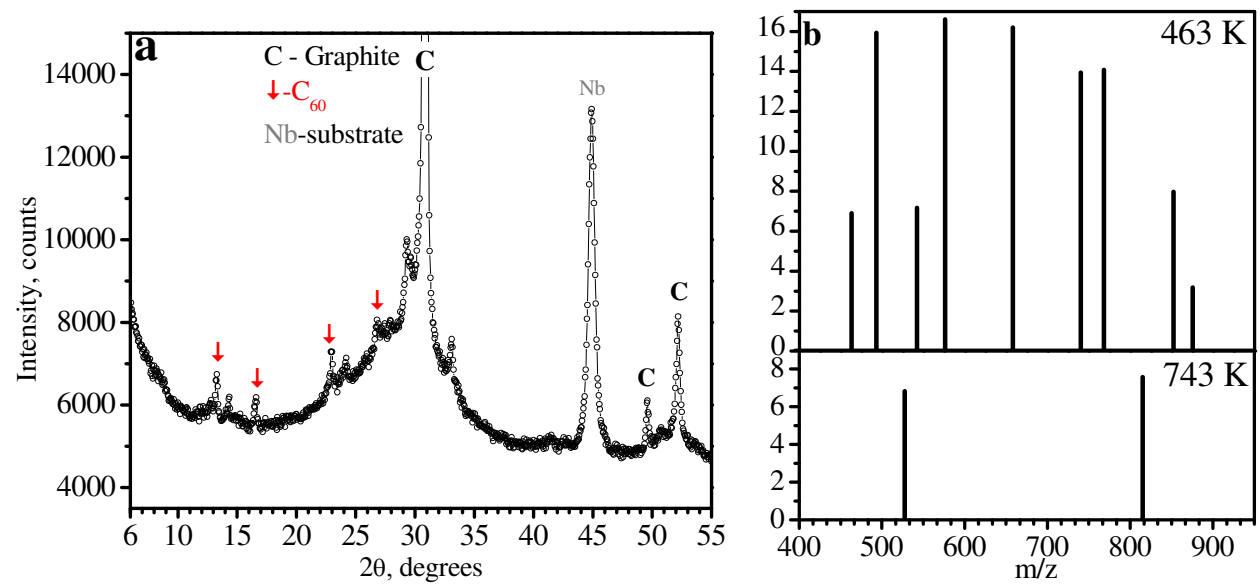

Fig. 7. Products of electrical explosion of graphite in ethanol (a) and toluene (b) with injected energy $10 \mathrm{~kJ} / \mathrm{g}<\mathrm{w}<20 \mathrm{~kJ} / \mathrm{g}$ :

a) fragment of the XRD diagram, Co Ka radiation,

б) mass spectra at different temperatures of emitter.

It was found that CNM synthesized by electric explosion of graphite have strong ferromagnetic properties, typical to ferromagnetic materials (type of nickel). The value of specific saturation magnetization is $\sim 57 \mathrm{~A} \mathrm{~m}^{2} / \mathrm{kg}$ at the temperature of liquid nitrogen and $20-30 \mathrm{~A} \mathrm{~m}^{2} / \mathrm{kg}$ at room temperature (Fig. 8a). The Curie temperature is $425 \mathrm{~K}$ (Fig. $8 \mathrm{~b}$ ). According to the chemical analysis, CNM have less than 2 wt.\% (0.5 at.\%) impurity of iron due to the erosion of the steel electrodes and the body of reactor during electroexplosion. This amount of iron can provide not more than $10 \%$ of the value of specific saturation magnetization which demonstrate CNM. In addition, the Curie temperature of iron $T_{c}$ is $1043 \mathrm{~K}$. Therefore, we can say with reasonable confidence that the magnetic properties of $\mathrm{CNM}$ are associated with ferromagnetic condition of carbon atoms but not iron impurities. It should be pointed out that the value of the specific saturation magnetization of this powder decreases in 2 order after 3 year storage on the air.

The information about existence of magnetic ordering in $\mathrm{CNM}$, but with a much smaller degree of specific magnetization (on a 2 orders), have recently appeared in literature (Makarova \& Palacio, 2006). At the present moment, there is no general theory that would explain the magnetic properties of CNM. At the extreme conditions of electrical explosion under impact of high temperatures and pressures, the specific electronic state of carbon atoms can result in a ferromagnetic state appearing.

In recent years a number of reports of observation of the magnetic ordering in different allotropic forms of carbon, such as in the fullerenes, fullerene hydrides, carbon nanotubes, nanocrystalline graphite and graphene (Makarova, 2004); Belavin et al. ,2004; Alexandre, 2008; Yazyev, 2008) are presented. Several possible mechanisms explaining this phenomenon are considering at the present: exchange magnetism perfect crystalline structure containing $\mathrm{sp}^{2}-\mathrm{sp}^{3}$ hybridized atoms; induced magnetism; the magnetism caused by structural imperfections in the various forms of carbon (Makarova \& Palacio, 2006; Ugeda, 2010). It is considered that under extreme conditions (such as high temperature and pressure, irradiation by fast particles, laser heating) special types of ordering of carbon atoms or defects in structure of CNM, 
favorable for the formation of the spontaneous ferromagnetic state, can appear. Such extreme conditions are typical for electroexplosion synthesis methods which can lead to a high degree of defectiveness of the crystal structure and the formation of specific electronic states of the synthesized products that make them ferromagnetic.
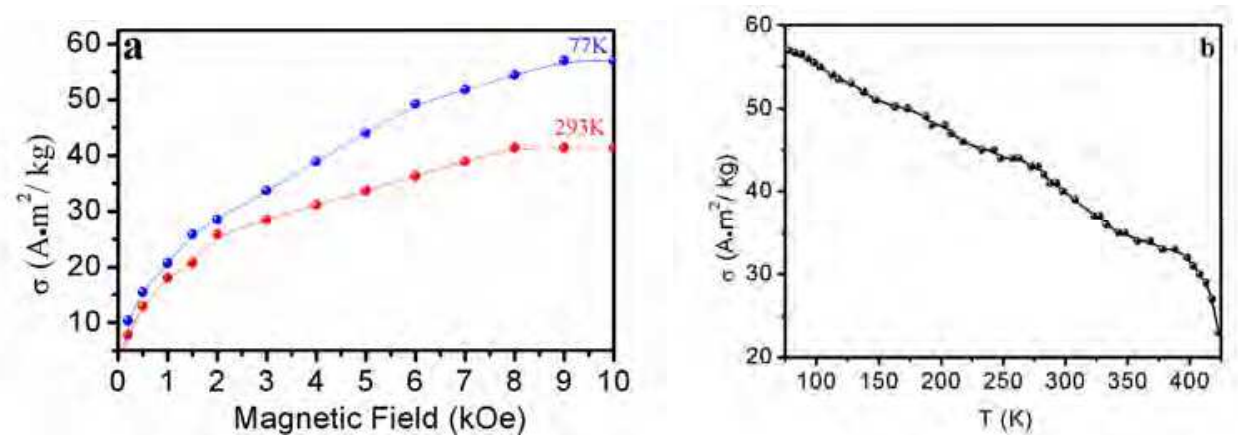

Fig. 8. The dependence of specific magnetization $(\sigma)$ of the graphite explosion products in toluene: a) vs applied magnetic field, b) vs temperature (saturation magnetic field $\mathrm{H}=10 \mathrm{kOe}$ ).

\section{Structure of amorphous carbon synthesized by an electric breakdown of organic liquids technology}

Impact of powerful current pulses on organic liquids results in initiation of a zone of high temperatures and pressures, in which a destruction of $\mathrm{C}-\mathrm{H}$ bonds in hydrocarbon molecules occurs with the formation of nanocarbon in solid state (Rud et al., 2011). The electric discharge treatment of hydrocarbons was conducted using standard high-voltage equipment (Fig. 2) in oscillation regime to realize an electrical breakdown of liquid dielectrics (the injected energies in the range $0.1-2 \mathrm{MJ} / 1$ ). The benzene and cyclohexane with the equal amount of carbon atoms and a different degree of their hybridization in the molecule were chosen as working media. The typical oscillograms of voltage and current in a discharge circuit are plotted at the Fig. 9.

The investigations of the products of EBOL synthesis completed by X-Ray diffractometry and Raman spectroscopy testify that they are typical amorphous carbon (Robertson, 2002; Boukalov et al. 2006; Casiraghi, 2005). The Raman spectra of the amorphous carbon produced from different types of organic liquids are characterized by intensive broad Gand D- bands. The standard positions of D $\left(1350 \mathrm{~cm}^{-1}\right)$ - and G $\left(1580 \mathrm{~cm}^{-1}\right)$-bands for graphite are indicated in Fig. 10. It is well known, that AC is characterized by very strong structural disorder. This structural parameter can be calculated from the ratio of intensities of D-and G-bands $-I_{D} / I_{G}$. It is clearly seen that the value of $I_{D} / I_{G}$ is very large for the both powders that proves a strong structural disorder (Table 1). Tuinstra and Koenig (Tuinstra \& Koening, 1970; Robertson, 2002) have shown that the $I_{D} / I_{G}$ value is inversely proportional to the block size $\mathrm{L}_{\mathrm{a}}$ along the direction $a$ :

$$
\frac{\mathrm{I}_{\mathrm{D}}}{\mathrm{I}_{\mathrm{G}}}=\frac{\mathrm{C}(\lambda)}{\mathrm{L}_{\mathrm{a}}}
$$

where $C(\lambda)$ is a wavelength-dependent pre-factor. 


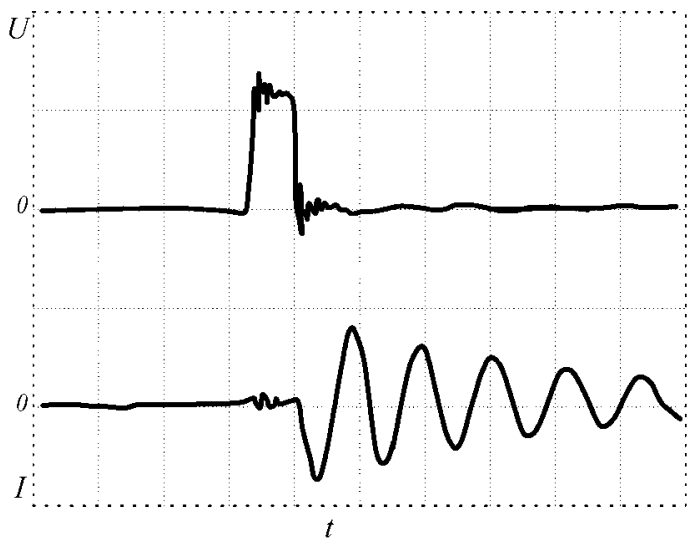

Fig. 9. Typical oscillograms of voltage (top) and current (bottom). $\mathrm{m}_{\mathrm{t}}=5 \mu \mathrm{s} /$ cell, $\mathrm{m}_{\mathrm{U}}=25 \mathrm{kV} /$ cell, $\mathrm{m}_{\mathrm{I}}=9.52 \mathrm{kA} /$ cell .

The sizes of blocks $\mathrm{L}_{\mathrm{a}}$ calculated from (27) are presented in Table 1. It is clearly seen that AC is characterized by a small blocks size, which practically does not depend on the type of working liquid.

\begin{tabular}{|c|c|c|c|c|c|c|}
\hline \multirow{2}{*}{$\begin{array}{c}\text { Working } \\
\text { liquid }\end{array}$} & \multicolumn{2}{|c|}{ G-band } & \multicolumn{2}{c|}{ D-band } & \multirow{2}{*}{$\mathrm{I}_{\mathrm{D}} / \mathrm{I}_{\mathrm{G}}$} & \multirow{2}{*}{$\mathrm{L}_{\mathrm{a}}, \AA$} \\
\cline { 2 - 5 } & Center, $\mathrm{cm}^{-1}$ & FWHM, $\mathrm{cm}^{-1}$ & Center, $\mathrm{cm}^{-1}$ & FWHM, $\mathrm{cm}^{-1}$ & & \\
\hline $\mathrm{C}_{6} \mathrm{H}_{6}$ & 1595 & 75 & 1353 & 101 & 1 & 43 \\
\hline $\mathrm{C}_{6} \mathrm{H}_{12}$ & 1585 & 69 & 1348 & 59 & 0.96 & 45 \\
\hline
\end{tabular}

Table 1. Data from Raman spectra of amorphous carbon synthesized in hydrocarbon liquids with different chemical nature (Center - the position of maximum, FWHM - full width at half height, $\mathrm{I}_{\mathrm{D}} / \mathrm{I}_{\mathrm{G}}$ - the ratio of the integrated intensities of D-and G-bands, $\mathrm{L}_{\mathrm{a}}$ - the size of the particles along the graphene plane)

The two additive broad bands at $1236 \mathrm{~cm}^{-1}$ and $1489 \mathrm{~cm}^{-1}$ are present in the Raman spectrum of the AC synthesized in cyclohexane (Fig.10) that indicates the presence of $\mathrm{sp}^{2}$ $\mathrm{sp}^{3}$ bonds and $\mathrm{CH}$ groups (Speight, 2004) in the material. There are only low-intensity bands at $1000-1100 \mathrm{~cm}^{-1}$ corresponding to the $\mathrm{C}-\mathrm{H}$ vibrations in an aromatic ring in the spectrum of the AC produced by electrical discharge treatment of benzene (Fig.10). It is associated with the use of benzene as a working medium for synthesis (Robertson, 2002; Speight, 2004). The data of Raman spectroscopy indicate the amorphous structure of the synthesized powders.

The traditional method of the structural analysis of amorphous materials is the method of radial distribution function (RDF) analysis (Elliot, 1984; Egami \& Billinge, 2003; Petkov, 1989). It is based on the relationship between the function of radial distribution of the atomic density $\rho(r)$ and the intensity of coherent X-ray scattering $I_{\text {ce }}$ which is expressed in the form of the integral equations:

$$
I_{\text {ce }}=N F^{2}+N F^{2} \int_{0}^{\infty} 4 \pi r^{2}\left[\rho(r)-\rho_{0}\right] \frac{\sin (s r)}{s r} d r
$$




$$
4 \pi r^{2} \rho(r)=4 \pi r^{2} \rho_{0}+\frac{2 r}{\pi} \int_{0}^{\infty} s[i(s)-1] \sin (s r) d s
$$

where $\mathrm{N}$ - is the number of the scattering atoms, $\mathrm{F}^{2}$ - the atomic factor, $\mathrm{i}(\mathrm{s})=\mathrm{I}_{\mathrm{ce}} / \mathrm{F}^{2}$ the structure factor, $\mathrm{I}_{\mathrm{ce}}$ - the coherent-scattered intensity in electron units, $\mathrm{s}$ - the diffraction vector, $2 \theta$ - the scattering angle, $4 \Pi r^{2} \rho(r)$ - the RDF function of atom density.

Calculated structure factors (SF) and RDF of AC synthesized by the EBOL technology in benzene and cyclohexane are shown on the Fig. 11. It is seen that AC produced in the benzene possesses clearly defined graphite-like type of short range order. The position and intensity of the second peak on SF for AC produced in cyclohexane (Fig. 11, left, bottom) testify to a possible presence of diamond-like type of short range order in its atomic structure.

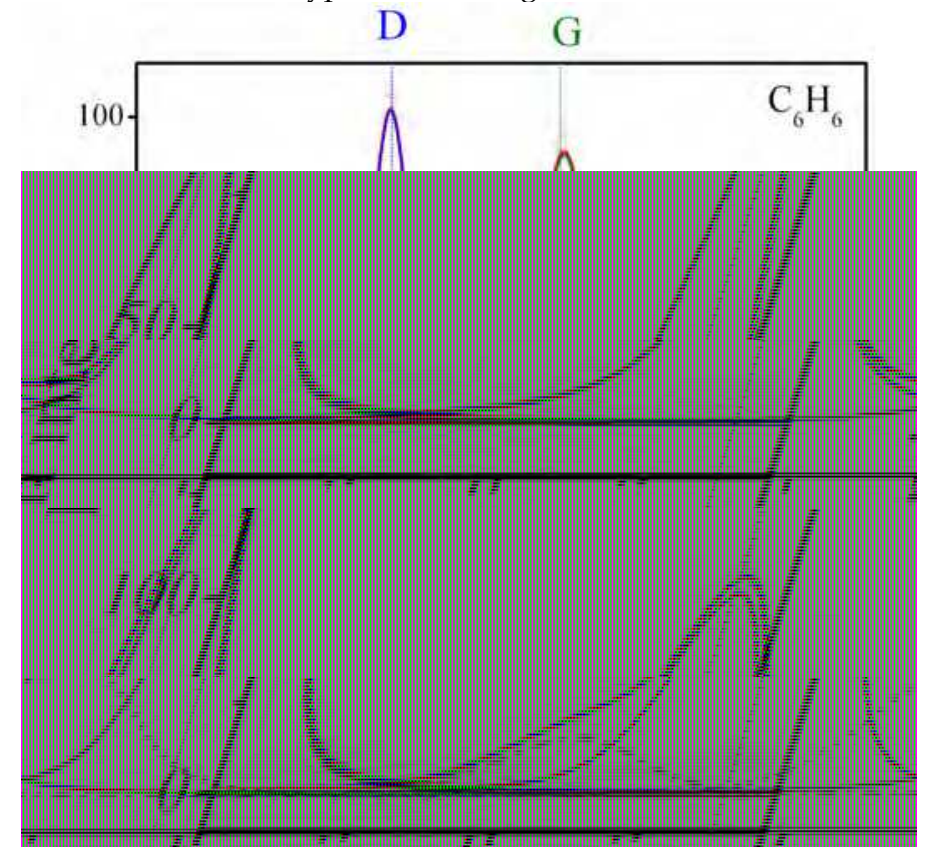

Fig. 10. Raman spectra $(\lambda=514 \mathrm{~nm})$ of the products of electrical breakdown of benzene (top) and cyclohexane (down). Standard position for D $\left(1350 \mathrm{~cm}^{-1}\right)$ and $\mathrm{G}\left(1581 \mathrm{~cm}^{-1}\right)$ bands of graphite are indicated by dotted lines.

The electron microscopic studies were carried out for more detailed characterization of produced materials. The products of electrical discharge processing of different hydrocarbon liquids are agglomerated powders with an extended surface $\left(\mathrm{S}_{\mathrm{BET}} \sim\right.$ $150 \mathrm{~m}^{2} / \mathrm{g}$ ) (Fig. 12a). High-resolution electron microscopy has shown that the individual particles have complex morphology which depends on the chemical nature of working liquid, that is, a carbon source. Thus, the micrographs of the AC, produced by electrical discharge treatment of benzene, clearly show a layered structure with a characteristic distance of $\sim 0.35$ $\mathrm{nm}$ between the individual layers (Fig. 12b). However, in the case of cyclohexane, the morphology of the particles is more complicated. Fig. 12c shows visible core up to $5 \mathrm{~nm}$ in size surrounded by a shell of about 5 layers with an interlayer distance of $\sim 0.36-0$. $37 \mathrm{~nm}$. This 
"core-shell" structure is typical onion-like carbon (Mykhaylyk et al., 2005; Shenderova et al., 2002; Shenderova \& Gruen, 2006;). It is worthy of note that separated onions are united into agglomerates with external common graphite-like shell.
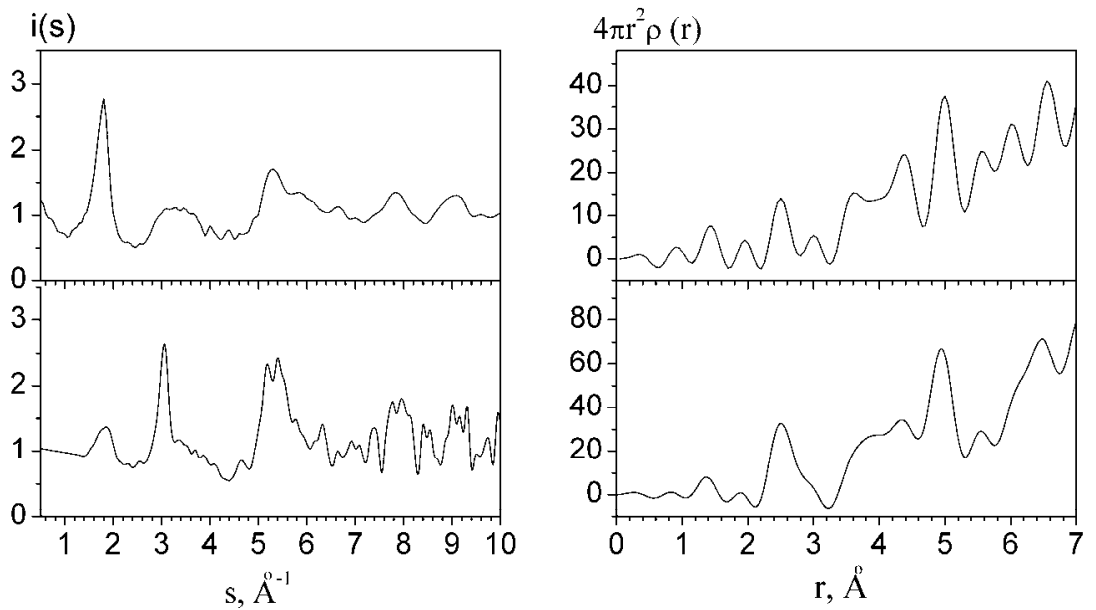

Fig. 11. SF (left) and RDF (right) of AC synthesized by the EBOL technology in benzene (top) and cyclohexane (bottom).
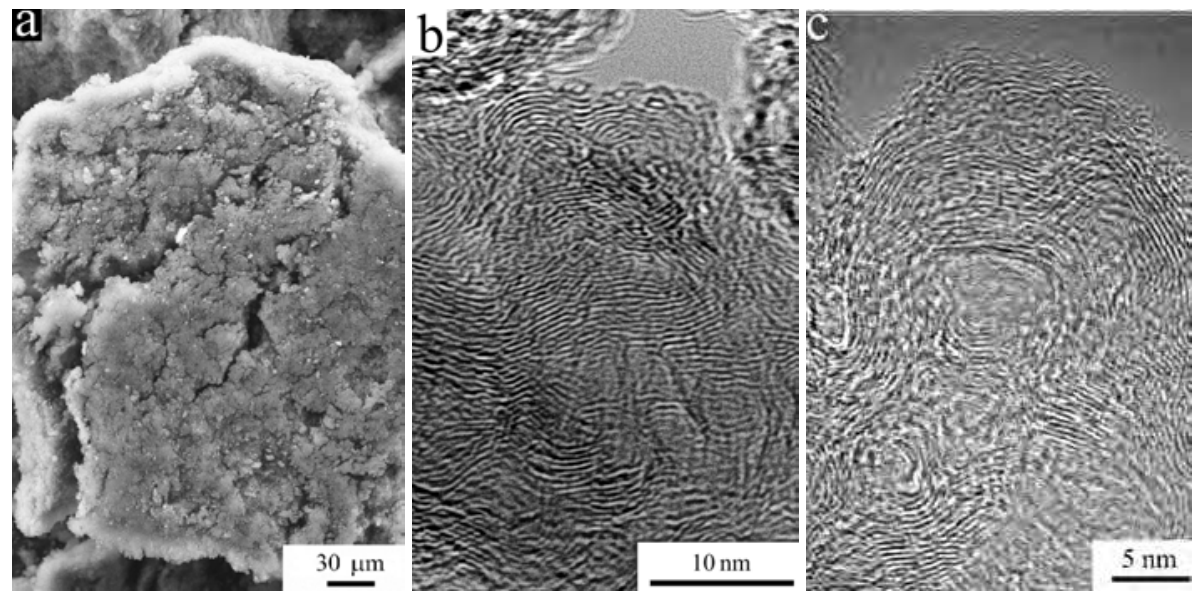

Fig. 12.Typical micrographs of products of electric discharge treatment of hydrocarbon liquids: (a) particle-agglomerate with a developed surface; $(b, c)$ morphology of particles produced in benzene (b) and cyclohexane (c).

\section{Conclusion}

The new electric discharge technologies using the methods of electrical wire explosion of graphite conductors and electric breakdown of organic liquids are developed to produce carbon nanomaterials, containing fullerene-like clusters of the $C_{60}-C_{70}$, nanotubes, 
nanodiamonds and amorphous carbon. The phase composition of CNM obtained could be effectively controlled by variation of the energy parameters of the synthesis process and chemical nature of the surrounding medium.

A model of formation of different phases of CNM during electroexplosion of graphite is proposed. Carbon nanotubes and fullerenes are formed from fragments of graphene, obtained from explosive fractured graphite, if the injected specific energy into graphite is substantially smaller than the graphite sublimation energy. Nanodiamonds are formed by phase transformation graphite-liquid-diamond, if the injected specific energy into sample is substantially greater than the graphite sublimation energy.

It was discovered that the synthesis products have strong ferromagnetic properties. The magnetization value of the synthesized carbon nanomaterials (about the $57 \mathrm{~A} \mathrm{~m}^{2} / \mathrm{kg}$ ) amounts the value close to that of pure nickel.

The structure of amorphous carbon synthesized by electric breakdown of organic liquids technique directly depends from chemical nature of the working medium - source of carbon. The fact of onion-like carbon synthesis by electric discharge treatment of cyclohexane is established. This technology enables to produce onion-like carbon in a large scale at normal conditions.

\section{Acknowledgment}

This work was partially supported by the joint projects of NASU-STCU (\# 4951).

\section{References}

Afanas'ev D.V., Baranov G.A., Belyaev A.A., Dyuzhev G.A. \& Zinchenko A.K. (2001). Producing fullerenes by evaporation of graphite stationary $\mathrm{CO}_{2}$-laser. Technical Physics Letters. Vol. 27. No10, (May 2001), C. 31 - 36, ISSN: 1063-7850, (in Russ.)

Alexandre S.S., Mazzoni M.S. \& Chacham H. (2008). Edge States and magnetism in carbon nanotubes with line defects. Physical Review Letters. Vol. 100, No. 14, (April 2008 ), pp. 146801 [4 pages], ISSN: 0031-9007

Belavin V.V., Bulusheva L.G., Okotrub A.V., \& Makarova T.L. (2004). Magnetic ordering in C60 polymers with partially broken intermolecular bonds. Physical Review B. Vol. 70, (October 2004), pp.155402 (5 pages), ISSN:1098-0121

Boukalov S.S., Mihaltsyn L.A., Zubavichus Y.V., Leytets L.A. \& Novikov Y.N. (2006). Investigation of the structure of graphite and other $\mathrm{sp} 2$ hydrocarbon materials by the methods of micro-Raman spectroscopy and X-ray diffraction. Rossijskij himicheskij zhurnal, Vol.1. No 1, pp. 83-91. ISSN 0373-0247, (in Russ.)

Bulgakov A.V., Bulgakova N.M., Burakov I.M. et al. (2009). Nanosized Material Synthesis by Action of High-Power Energy Fluxes on Matter, Kutateladze Institute of Thermophysics, ISBN: 978-5-89017-010-1, Novosibirsk, (in Russ.).

Casiraghi C., Ferrari A. C. \& Robertson J. (2005). Raman spectroscopy of hydrogenated amorphous carbon. Physical Review B, Vol. 72. No.8, (August 2005), pp. 085401 [14 pages]. ISSN: 1098-0121

Egami T. \& Billinge S.J.L. (Eds.). (2003). Underneath the Bragg Peaks. Pergamon, ISBN: 080426980, UK

Eletskii A.V. \& Smirnov B.M. (1995). Fullerenes and carbon structures. Physics-Uspekhi, Vol. 38, (September, 1995), pp. 935-964, ISSN: 0320 - 0116

Elliot S.R. (1984). Physics of amorphous materials, Longman, ISBN 0-582-44636-8, USA. 
Gogotsi Y. (Ed.). (2006). Nanomaterials Handbook, Taylor \& Francis Group, ISBN: 0-8493-23088 , Boca Raton

Guozhong Cao. (2004). Nanostructures \& Nanomaterials: Synthesis, Properties \& Applications, Imperial College Press, ISBN: 1860944159, London

Kuskova N.I., Tkachenko S.I., Koval S.V. (1997). Investigation of liquid metallic wire heating dynamics. Journal of Physics: Condensed Matter. Vol. 9, No. 29, (September 1996), pp. 6175 - 6184, ISSN: 0953-8984

Kuskova N.I. (2005). Phase Transformations of Carbon Heated at High-Power Current Pulse. Technical Physics Letters. Vol. 31, No 17, (February 2005), pp. 28-32. ISSN 1063-7842

Kuskova N.I., Rud A.D., Baklar V.U. \& Ivaschuk L.I. (2010). Physical aspects of the formation of various allotropic forms of nano-sized carbon in the process of electrical explosion. Technical Physics. Vol. 80, No. 9, (December 2009), pp. 57 - 62, ISSN: 0044-4642

Makarova T.L. (2004). Magnetic properties of carbon nanostructures. The Overview. Fizika $i$ Tekhnika Poluprovodnikov. Vol 38, No. 6, (December 2003), pp. 641 - 664, ISSN: 00153222 (in Russ.)

Makarova T. \& Palacio F. (Eds.). (2006). Carbon Based Magnetism: An Overview of the Magnetism of Metal Free Carbon-based Compounds and Materials, Elsevier Science, ISBN: 0444519475

Mykhaylyk O.O., Solonin Y.M., Batchelder D.N. \& Brydson R. (2005). Transformation of nanodiamond into carbon onions: A comparative study by high-resolution transmission electron microscopy, electron energy-loss spectroscopy, x-ray diffraction, small-angle x-ray scattering, and ultraviolet Raman spectroscopy. $J$. Appl. Phys. Vol. 97, No. 7, (January 2005), pp. 074302 (16 pages). ISSN: 0021-8979

Petkov V. (1989). RAD, a program for analysis of X-ray diffraction data from amorphous materials for personal computers. Journal of Applied Crystallography. Vol. 22, No. 4, (August 1989), pp. 387-389, ISBN: 0021-8898

Rud A.D., Perekos A.E., Ogenko V.M., Shpak A.P., Uvarov V.N., Chuistov K.V., Laknhik A.M., Voinash V.Z. \& Ivaschuk L.I. (2007). Different state of carbon produced by high-energy plasmochemistry synthesis. Journal of Non-Crystalline Solids. Vol. 353, No. 32 - 40, (October 2007), pp. 3650 - 3654, ISSN: 0022-3093

Rud A.D., Kuskova N.I., Ivaschuk L.I., Zelinskaya G.M. \& Biliy N.M. (2011). Structural State of carbon nanomaterials Produced by High-Energy Electric Discharge Techniques. Fullerenes, Nanotubes, and Carbon Nanostructures, Vol. 19, No. 1, (January 2011), pp. 120 - 126, ISSN $1536-383 X$

Robertson J. (2002). Diamond-Like carbon. Materials Science and Engineering: R: Reports. Vol. 37, No. 4 - 6, (May, 2002) pp.129 - 281. ISSN: 0927-796X

Shenderova O.A \& Gruen D.M. (Eds.). (2006). Ultrananocrystalline Diamond: Synthesis, Properties and Applications. William Andrew Publishing, ISBN 0815515243 . Norwich, NY.

Shenderova O.A., Zhirnov V.V. \& Brenner D.W. (2002). Carbon nanostructures. Critical Reviews in Solid State and Materials Sciences. Vol. 27, No.3/4, pp. 227-356. ISSN: 1040-8436

Speight J. G. (Ed.). (2004). Lange`s Handbook of chemistry. 16th Edition, McGraw-Hill Professional, ISBN 0-07-143220-5, New York.

Tuinstra F. \& Koening J.L. (1970). Raman Spectrum of Graphite. Journal of Chemical Physics., Vol. 53, (November 1969), pp.1126-1130. ISSN 0021-9606

Ugeda M. M., Brihuega I., Guinea F., \& Gómez-Rodríguez J. M. (2010). Missing Atom as a Source of Carbon Magnetism. Physical Review Letters. Vol. 104, No. 9, (March 2010), pp. 096804 [4 pages], ISSN 0031-9007

Yazyev O.V. (2008). Magnetism in Disordered Graphene and Irradiated Graphite. Physical Review Letters. Vol. 101, No. 3, (July 2008), pp. 037203 [4 pages], ISSN 0031-9007 


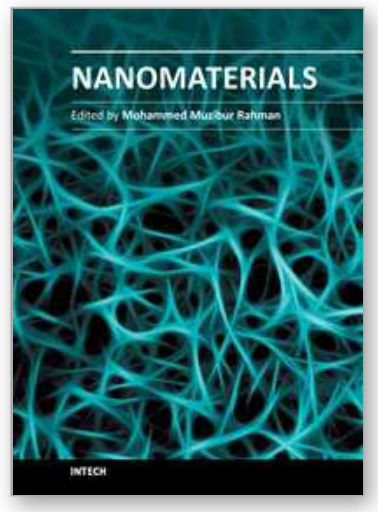

\author{
Nanomaterials \\ Edited by Prof. Mohammed Rahman
}

ISBN 978-953-307-913-4

Hard cover, 346 pages

Publisher InTech

Published online 22, December, 2011

Published in print edition December, 2011

The book "Nanomaterials" includes all aspects of metal-oxide nano-structures, nano-composites, and polymer materials instigating with materials survey and preparations, growth and characterizations, processing and fabrications, developments and potential applications. These topics have utilized innovative methods of preparation, improvement, and continuous changes in multidimensional ways. The innovative frontiers are branching out from time to time to advanced nanotechnology. It is an important booklet for scientific organizations, governmental research-centers, academic libraries, and the overall research and development of nano-materials in general. It has been created for widespread audience with diverse backgrounds and education.

\title{
How to reference
}

In order to correctly reference this scholarly work, feel free to copy and paste the following:

A. D. Rud, N. I. Kuskova, L. I. Ivaschuk, L. Z. Boguslavskii and A. E. Perekos (2011). Synthesis of Carbon Nanomaterials Using High-Voltage Electric Discharge Techniques, Nanomaterials, Prof. Mohammed Rahman (Ed.), ISBN: 978-953-307-913-4, InTech, Available from:

http://www.intechopen.com/books/nanomaterials/synthesis-of-carbon-nanomaterials-using-high-voltageelectric-discharge-techniques

\section{INTECH}

open science | open minds

\author{
InTech Europe \\ University Campus STeP Ri \\ Slavka Krautzeka 83/A \\ 51000 Rijeka, Croatia \\ Phone: +385 (51) 770447 \\ Fax: +385 (51) 686166 \\ www.intechopen.com
}

\author{
InTech China \\ Unit 405, Office Block, Hotel Equatorial Shanghai \\ No.65, Yan An Road (West), Shanghai, 200040, China \\ 中国上海市延安西路65号上海国际贵都大饭店办公楼405单元 \\ Phone: +86-21-62489820 \\ Fax: +86-21-62489821
}


(C) 2011 The Author(s). Licensee IntechOpen. This is an open access article distributed under the terms of the Creative Commons Attribution 3.0 License, which permits unrestricted use, distribution, and reproduction in any medium, provided the original work is properly cited. 